\title{
Review
}

\section{The functions of mucosal $T$ cells in containing the indigenous commensal flora of the intestine}

\author{
A. J. Macpherson*, M. M. Martinic and N. Harris \\ Institute of Experimental Immunology, Universitätsspital, Schmelzbergstrasse 12, 8091 Zürich (Switzerland), \\ Fax +41 1255 4420, e-mail: amacpher@pathol.uniz.ch
}

Received 9 August 2002; accepted 9 September 2002

\begin{abstract}
There is an immense load of non-pathogenic commensal bacteria in the distal small intestine and the colon of mammals. The physical barrier that prevents penetration (translocation) of these organisms into the body is a simple epithelium comprised of the single enterocyte/colonocyte cell layer with its overlying mucus. In
\end{abstract}

this review, we discuss the roles of intestinal $\mathrm{T}$ cells in initiating and regulating innate and adaptive mucosal immune responses of the mucosal immune system that avoid or limit penetration of the commensal intestinal bacteria.

Key words. Intraepithelial lymphocyte; lamina propria lymphocyte; IgA; commensal bacteria: macrophage: intestinal mucosa.

\section{Introduction}

The mucosal immune system of the intestine is constantly exposed to an immense load of non-pathogenic commensal intestinal bacteria, which reach a density of $10^{12}$ organisms per gram of intestinal contents in the lower small intestine and the colon. The physical barrier that separates these bacteria from the remainder of the body consists of a single layer of epithelial cells and overlying mucus. This physical barrier can easily be damaged by mucosal infections, systemic disease or drugs (including alcohol!) [1], so how does the immune system in the intestinal mucosa and the rest of the body deal with those bacteria that penetrate the epithelium? The answer lies in the interplay between adaptive (inducible) and innate (constitutive) mucosal immunity: whilst we know some of the details, we are inferring many others by extrapolating from the immune responses mounted against pathogens. Research on interactions between the mammalian host and its symbiotes is an exciting and rapidly evolving field.

\footnotetext{
* Corresponding author.
}

Why are intestinal immune barriers against the commensals important? First, although these bacteria are normally harmless, they can become pathogens and cause serious infections in patients who are debilitated and immunocompromised, for example, in individuals on immunosuppression or chemotherapy, or in the elderly. Second, the commensal bacteria contain enormous numbers of immunostimulatory molecules (e.g. lipopolysaccharide or repetitive unmodified $\mathrm{CpG}$ DNA motifs) which would seriously compromise the host if microorganisms penetrated in sufficient numbers. Third, the relative amounts of circulating immunoglobulin, especially of the $\operatorname{IgG}$ and $\operatorname{IgA}$ isotypes, are affected by the presence of commensal bacteria in the intestine [2-5]. The primary repertoire of B cells (the relative numbers of B cells that are available to respond to different antigens before a pathogenic challenge is encountered) are profoundly influenced by the numbers of commensals that penetrate mucosal defences $[6,7]$. The changes in the primary $\mathrm{B}$ cell repertoire resulting from excessive penetration may later impair the ability of a naive individual to survive a pathogen [8], or, by generating particular specificities, in- 
crease the risk of later inappropriate reactions, possibly precipitating autoimmune disease [9].

This review focuses on the relative importance of mucosal $\mathrm{T}$ cells. To dissect the different potential immune barriers, the interactions between mucosal $\mathrm{T}$ cells and other principal cell types in the intestinal mucosa (B cells, macrophages, dendritic cells, epithelial cells and endocrine cells) will be discussed in individual sections. First, we must review the cellular content of the mucosal immune system, and how it is influenced by the presence of intestinal bacteria.

The cellular content of the intestinal mucosal immune system is shaped by the presence of intestinal bacteria The impact of intestinal commensal bacteria on the cellular composition of the mucosal immune system can be assessed by comparing the intestines of animals that are bred and maintained in entirely gnotobiotic (germ-free) conditions with genetically identical animals which do have intestinal bacteria, but are kept free of intestinal and systemic pathogens (specific pathogen free, SPF). Compared with animals that have an SPF intestinal flora, the germ-free intestine is characterised by very low numbers of IgA-secreting plasma cells in the lamina propria and has small atrophic Peyer's patches with few germinal centres $[10,11]$.

There are three principal locations of $\mathrm{T}$ lymphocytes in the mucosal immune system: (i) within Peyer's patches, (ii) as intraepithelial lymphocytes (IELs) lying between or immediately underneath the layer of enterocytes and (iii) as lamina propria $\mathrm{T}$ cells which lie between the villi or crypts away from the epithelial layer. These are all affected to some extent by germ-free conditions. The Peyer's patches contain $\mathrm{T}$ cell areas with $\mathrm{CD} 4^{+}$or $\mathrm{CD} 8^{+}$ cells which use the $\alpha \beta$ T cell receptor (TCR), which are diminished along with a generally reduced lymphocyte cellularity [11].

The IELs are a heterogeneous group, which comprise members that use the $\gamma \delta \mathrm{TCR}$, and those which use the $\alpha \beta$ TCR. The $\alpha \beta$ TCR IELs can also be subdivided into two major groups - those which express CD8 as a heterodimer with two different ( $\alpha$ and $\beta$ ) subunits $(\mathrm{CD} 8 \alpha \beta)$, and those which express CD8 as an $\alpha$ homodimer $(\mathrm{CD} 8 \alpha \alpha)$ [12]. (There are also smaller numbers of IELs with other phenotypes including $\alpha \beta$ TCR CD4 ${ }^{+} \mathrm{CD} 8 \alpha \alpha^{+}$, $\alpha \beta$ TCR CD $^{+}{ }^{+} \mathrm{CD}^{-}$and $\alpha \beta$ TCR CD $\left.^{-} \mathrm{CD}^{-}\right)[13,14]$. Of these different sorts of IEL, the $\gamma \delta$ TCR CD $8 \alpha \alpha$ are numerically relatively unaffected by germ-free conditions [12, 15-17], whereas others (notably the $\alpha \beta \mathrm{TCR}$ $\mathrm{CD} 8 \alpha \beta)$ are reduced $[12,15-17]$ and the age-related increase of the $\alpha \beta \mathrm{TCR} \mathrm{CD} 4^{+} \mathrm{CD} 8^{+}$double positive fraction does not occur [18]. There are some data suggesting that $\alpha \beta$ TCR CD $8 \alpha \alpha$ IELs are reduced in germ-free animals and increase to normal levels when the animals acquire a normal intestinal flora (conventionalisation), although in this study, the CD8 $\alpha \alpha$ numbers were determined indirectly from the difference between total CD8 and $\mathrm{CD} 8 \beta$ values [15]. Increased oligoclonality (skewing of the repertoire of $\mathrm{V} \beta$ TCR chain usage) in CD $8 \alpha \alpha$ IELs following conventionalisation has also been found [16]. Because $\mathrm{CD} 8 \alpha \alpha$ molecules do not seem to interact with classical major histocompatibility complex (MHC) class I complexes in the same way as $\operatorname{CD} 8 \alpha \beta$ [19], responses of $\mathrm{CD} 8 \alpha \alpha$ IELs to conventionalisation suggest that there are non-classical 'adaptive' responses to the introduction of commensal bacteria, although the functional consequences are incompletely understood as discussed in the next section. Such non-classical 'adaptation' seems to be a small component of the picture, because in most papers, the CD $8 \alpha \beta$ IEL fraction changes most when germ-free and conventional intestinal tissues are compared $[12,16,17]$.

The $\mathrm{T}$ cell component of the lamina propria is largely composed of $\mathrm{CD}^{+}(\alpha \beta \mathrm{TCR})$ lymphocytes and these are also considerably reduced in germ-free conditions and restored to normal levels by conventionalisation $[16,17$, 20].

Thus the cellular content of the mucosal immune system is profoundly shaped by the presence of the commensal intestinal bacterial flora. T and B cells in the Peyer's patches, IgA-secreting plasma cells in the lamina propria, CD4 lamina propria $\mathrm{T}$ cells and $\mathrm{CD} 8 \alpha \beta$ and $\mathrm{CD} 8 \alpha \alpha$ $(\alpha \beta$ TCR) T cells in the intraepithelial compartment are all present in normal numbers only when bacteria are present in the intestinal lumen.

\section{Both the thymically selected and components of the thymic-independent $T$ cell repertoire contribute to the cells that are responsive to the presence of commensal bacteria}

Most of the $\mathrm{T}$ cells in the systemic (non-mucosal) immune system mature in the thymus and are subject there to selection mechanisms. Once the precursor $\mathrm{T}$ cells (CD4- ${ }^{-} D 8^{-}$double negative) enter the thymus, they successively undergo positive and negative selection - both depend on an interaction between the $\alpha \beta$ TCR and peptide antigen loaded onto the MHC class I or II molecules on cortical and medullary epithelial cells. This process allows the cells that are successful to proceed sequentially through the stages of $\left(\mathrm{CD}^{+}\right) \mathrm{CD}^{+} \mathrm{CD}^{+}$(double positive) and $\mathrm{CD}^{+}{ }^{+} \mathrm{CD} 8^{-}$or $\mathrm{CD}^{-}{ }^{-} \mathrm{CD} 8^{+}$(single positive), and they leave the thymus at the mature single-positive stage. Experiments using radiation chimeras [21-23] and TCRtransgenic animals with fixed (and known) TCR specificity [24-27] showed that the positive selection stage required low affinity interactions between self MHC and self peptides; in other words, only those T cells possessing $\alpha \beta$ receptors capable of recognising peptides on the 
surface of self MHC (which is required for their later functionality) were able to develop. Conversely, other experiments with TCR transgenics [25-27] showed that the negative selection process caused deletion of those T cells which had a high affinity for interactions between self peptides and self MHC - in this case, a failsafe mechanism which avoids large numbers of circulating potentially autoimmune $\mathrm{T}$ cells.

A number of lines of evidence show that these selection and $\mathrm{T}$ cell development mechanisms do not apply equally to all intestinal $\mathrm{T}$ cells.

1) Experiments were carried out in lethally irradiated mice in which the thymus had been removed (so endogenous bone marrow and thymic tissues were destroyed): they were then reconsitituted with donor bone marrow of a compatible type but producing immunologically recognisable cells from a different mouse. Here, most of the T cells peripherally, and in the mucosa, failed to develop because the thymus was absent; however IELs of the CD $8 \alpha \alpha$ class (expressing either $\gamma \delta$ or $\alpha \beta \mathrm{TCR}$ ) were found in normal numbers [12]. In some similar experiments, reconstitutions of IELs of the $\mathrm{CD} 8 \alpha \beta$ and CD4 subtypes and lamina propria $\mathrm{CD} 4$ cells from donor bone marrow were achieved [14], although these experiments were complicated by the radio-resistance of the intestinal lymphocyte compartment [12]. From studies of intestinal lymphocytes in mice in which the MHC class I genes have been deleted it is clear that whereas the $\operatorname{CD} 8 \alpha \beta \alpha \beta$ TCRs are dependent on MHC class I for their development, $\mathrm{CD} 8 \alpha \alpha \operatorname{TCR} \alpha \beta$ and $\mathrm{CD} 8 \alpha \alpha \operatorname{TCR} \gamma \delta$ cells are independent of classical class I molecules [28].

2) Some strains of mice lose certain types of TCR from their peripheral repertoire because these receptors generically interact with self antigens expressed as a result of persistent retrovirus infection. CD8 $\alpha \alpha$ IELs are spared from these deletions (e.g. V $\beta 6$ cells from DBA/ 1 mice or $\mathrm{V} \beta 11$ cells from Balb/c strains). This means that potentially self-reactive TCR remain in the repertoire of this subset of IELs [14]. Indeed, experiments in mice transgenic for TCRs specific for the (male) HY antigen show that the CD8 $\alpha \alpha$ IEL compartment develops far better in male than in female animals, indicating that self antigen is a sufficient stimulus for selection of these cells [29, 30].

3) Mucosal T cells are affected in very different ways in mice that contain spontaneous or targeted genetic abnormalities that cause defective formation of secondary lymphoid structures. For example, in alymphoplastic mice which lack Peyer's patches and lymph nodes [31,32], the structure of the spleen and thymus is disrupted, there are no plasma cells secreting IgA in the intestine, and $\alpha \beta$ TCR CD4 $4^{+}$lamina propria lymphocytes are deficient [33; A. J. Macpherson and T.
Uhr, unpublished data]. Despite the abnormalities in intestinal lymphoid structures that have been classically viewed as the inductive site for both mucosal B and T cells, the content of CD $8 \alpha \alpha$ IELs expressing either $\alpha \beta$ or $\gamma \delta$ TCRs is normal [34].

The interpretation of these data has been that some intestinal T cells (notably the $\mathrm{CD} 4^{+} \mathrm{T}$ cells and the $\mathrm{CD} 8 \alpha \beta$ $\mathrm{T}$ cells) are induced in the classical manner (i.e. requiring conventional positive and negative selection mechanisms through the thymus, and homing to the intestinal mucosa after triggering either in mucosal lymphoid follicles or at peripheral sites) and others (notably the $\mathrm{CD} 8 \alpha \alpha$ lymphocytes) are quite independent of these mechanisms. Other in vivo experiments examined the mixing of different sorts of lymphocytes in parabiotic mice that had been fused into a Siamese relationship by wiring the scapulae together and anastomosing skin flaps. Using immunological markers to distinguish the migration of lymphocytes between the two animals, the splenic and Peyer's patch lymphocytes from each mouse mixed rapidly (within about 10 days), but IELs and to a lesser extent lamina propria lymphocytes were largely confined to each original animal (in the 38-day time frame of the experiment) [14]. The interpretation (that remains controversial [35]) is that the intestine itself may be a site of intestinal T lymphopoiesis in the adult animal, since even the emigration of precursor $\mathrm{T}$ cells from the bone marrow would be expected to mix the cell types between the two parabiotic animals. It is true that a significant proportion of the $\mathrm{T}$ cells (particularly the $\operatorname{CD} 8 \alpha \beta$ fraction) found in the intraepithelial compartment have been induced in the mucosa and then recirculated through the mesenteric/thoracic duct lymph and the blood before homing back to the mucosa [36].

There are therefore two major issues for the 'atypical' intestinal $\mathrm{T}$ cells that are not selected through conventional mechanisms. First, if the intestine is a site of T cell lymphopoiesis for these cells, where does it occur? In the mid 1990s, a 'new' lymphoid structure in the intestine was described - the intestinal cryptopatch - which is present in the alymphoplastic strain that lacks Peyer's patches and other conventional extrasplenic secondary lymphoid structures [35]. These cryptopatches contain $\mathrm{T}$ lymphocytes, and when painstakingly extracted, the constituent cells (lacking markers for mature $\mathrm{T}$ or B lymphocytes or myeloid cells) can reconstitute the intestinal T cell compartment in scid mice [37].

The second question concerns the ligands that potentially bind the TCRs or other signalling molecules of the CD $8 \alpha \alpha$ IELs class. This has been approached by looking at which molecules can be targeted in mice to diminish or remove the $\mathrm{CD} 8 \alpha \alpha$ IELs. Results have shown that whereas $\operatorname{CD} 8 \alpha \alpha \operatorname{TCR} \alpha \beta$ intestinal T cells are independent of classical MHC class I $\alpha$ chain molecules K and D, 
and the non-classical MHC class I molecule CD1d, they are much reduced in mice that lack the TAP transporter [38] (required to load peptides onto MHC class I) or in animals lacking $\beta_{2}$-microglobulin (which is a component of classical and non-classical MHC class I complexes) [39]. Deletion of another non-classical class I molecule, Qa-2, resulted in loss of both CD8 $\alpha \alpha$ IELs and (possibly as an indirect effect of the $\mathrm{CD} 8 \alpha \alpha$ reduction) $\mathrm{CD} 8 \alpha \beta$ cells [38]. Another non-classical molecule that has been investigated in ex vivo assays is thymus leukaemia antigen (TL). CD8 $\alpha \alpha$ is bound by TL tetramer complexes and TL-transfected cell lines show enhanced cytokine production (but not proliferation or cytotoxicity) by $\mathrm{CD} 8 \alpha \alpha$ cells. This suggests that non-classical MHC class I molecules such as TL may interact with CD $8 \alpha \alpha$, which unlike CD $8 \alpha \beta$ acts largely independently of the interactions between $\alpha \beta$ TCRs and peptide loaded onto classical class I MHC [19].

In summary, mainly conventionally selected and triggered intestinal $\mathrm{T}$ cells are responsive to the presence of commensal bacteria in the intestine, judged by the differences in $\mathrm{T}$ cell composition between germ-free animals and those with an intestinal flora. However, these changes in conventional thymic-dependent $\mathrm{T}$ cells are not entirely the result of immune priming by commensals, because experiments in germ-free mice transgenic for SV40 large $\mathrm{T}$ antigen under the control of the fatty acid-binding protein promoter show that enforced cell cycle re-entry of epithelial cells causes an influx of $\alpha \beta$ TCR CD $8 \alpha \beta$ and $\alpha \beta$ TCR CD4 cells, so some of the effects of the microflora on the intestinal $\mathrm{T}$ cell content are probably indirect [40]. Although $\gamma \delta \mathrm{TCR}$ cells are unresponsive to the presence of commensal bacteria, there is some increase in the non-conventional CD8 $\alpha \alpha$ compartment and skewing of the $\alpha \beta$ TCR repertoire on these cells when formerly germ-free animals become colonised $[15,16]$. The significance of this in terms of known signalling pathways of CD $8 \alpha \alpha$ TCR $\alpha \beta$ cells, and its functional consequences for limiting penetration of commensal intestinal bacteria, remain unknown.

\section{The role of $\mathrm{T}$ lymphocytes per se in limiting the penetration of commensals into the intestine}

The penetration of non-pathogenic bacteria from the intestine into underlying tissues of the body is defined as 'translocation'. There is evidence that in humans without obvious mucosal disease, commensal organisms can be cultured from the mesenteric lymph nodes [41]. High levels of translocation of commensals is presumably the reason that these organisms are frequently responsible for systemic sepsis in immunosuppressed patients, particularly those undergoing chemotherapy or bone marrow transplantation, and in patients with end-stage AIDS [42, 43].
Translocation has also been studied in experimental animals, where commensal organisms are not cultured from mesenteric lymph nodes or other systemic tissues of 'wild-type' immunocompetent animals, but are spontaneously translocated to the mesenteric lymph nodes, spleen, liver and kidneys in T-cell deficient athymic (nude) mice [44]. Such translocation also occurs in animals depleted of CD4 or CD8 T cells, and can be avoided if purified CD4 or CD8 cells are restored by adoptive transfer into these depleted animals [45, 46]. We have found similar high levels of penetration of commensal bacteria in mice that are T cell deficient as a result of targeted lesions of the $\beta$ and $\delta$ TCR genes [TCR $\beta^{--} \delta^{--}$; A. J. Macpherson unpublished data]. The mechanisms that might underlie these effects are not known, but the main possibilities are (i) that macrophages are activated by $\mathrm{T}$ cells within the intestinal lamina propria and phagocytosis prevents deeper penetration of bacteria; (ii) interaction between $\mathrm{T}$ and $\mathrm{B}$ cells in the production of secretory $\operatorname{Ig} \mathrm{A}$ which limits penetration of commensals through the epithelial cell layer, or, having penetrated become bound to secretory IgA and are transported back to the luminal surface during the secretory process; (iii) T cells are required to maintain the integrity of the epithelial cell layer. Each of these will be discussed in detail in the following sections.

What happens if all the immune and structural barriers fail and commensals reach the systemic circulation? There are no serious consequences if the bactericidal mechanisms of phagocytes are unimpaired. However, systemic spread of commensals is fatal in mice deficient for microbiocidal enzymes. This has been studied in mice with two targeted genetic lesions affecting both phagocyte oxidase (which results in the production of oxygen free radicals) and the inducible form of nitric oxide [47]; these gp91phox ${ }^{-/-} / \mathrm{NOS}^{-/-}$mice on the C57BL/6 background cannot kill phagocytosed microorganisms, and succumb to sepsis from commensal bacteria by the age of 4 weeks, despite pathogen-free conditions and prophylactic antibiotic usage.

\section{T lymphocyte activation of phagocytosis}

Endocytosis is a phylogenetically ancient cellular mechanism, and as phagocytosis has been adapted for protection from bacteriaemia in vertebrates. A healthy, intestinal lamina propria contains relatively few neutrophils, but macrophages are abundant, and these are extremely important in eliminating those bacteria that penetrate the physical and immunological intestinal defences. The data showing this are largely indirect, from studying the mechanisms that bacterial pathogens use to avoid being eliminated by macrophages. For example, the survival strategy of Shigella involves triggering macrophage apoptosis 
through caspase 1 induction by IpaB [48]; this and the inflammatory response generated allows Shigella to access and penetrate the basolateral sides of the epithelial cells [49]. Salmonella is able to interrupt the maturation of the endocytic compartment of its host via the gene products of its pathogenicity island 2 (SPI2), and since there is no maturation to late lysosomes (and neither mannose-6-phosphate receptors nor cathepsins D or L are acquired), the bacteria are not killed and facultative intracellular parasitosis is achieved. Alternatively, Salmonella can activate caspase-1 via the SipB gene product and hence cause macrophage apoptosis [49]. Yersinia also has a antiphagocytic strategy through (i) YopH, a tyrosine phosphatase which dephosphorylates three proteins required for phagocytotic cytoskeletal complexes - paxilin, p130cas and focal adhesion kinase [50]; (ii) YopT which causes actin filament depolymerisation [51], and (iii) YopE which inhibits Rho GTPases required for phagocytosis [52].

These examples show the critical importance of phagocytic functions of the monocyte/macrophage lineage in the host response when bacteria have penetrated the mucosa, which must be evaded as part of the requirement for pathogenicity. Since commensal organisms are not normally pathogenic, they have apparently found their evolutionary niche without subverting the phagocytic process, presumably because the consequence of intracellular survival would be disadvantageous - it would cause intestinal inflammation and thereby disrupt the biofilms or planktonic densities of the organisms in the intestinal mucus. Highly functional macrophage bactericidal activity thereby ensures true symbiosis, keeping the commensals right on the edge of the immune system and rapidly eliminating those that penetrate the mucosa. When macrophage bactericidal mechanisms are defective, commensals cause serious systemic sepsis [47].

To understand the probable interactions between $\mathrm{T}$ cells and macrophages in protection against the commensal microflora, we again need to take lessons from infectious pathology. The relevant infectious models are of endosomal pathogens, as commensals probably have little or no ability to invade the cytosol, so there is presumably little requirement for cytotoxic $\mathrm{T}$ cell induction $\left(\mathrm{CD} 8^{+}\right.$, $\alpha \beta \mathrm{TCR})$ that is crucial for Listeria monocytogenes and rickettsial infection control. Experiments with Mycobacterium tuberculosis have shown that interferon- $\gamma$ (IFN- $\gamma$ ) is critical to activate macrophages to exhibit bacteriocidal or bacteriostatic activity (through production of reactive nitrogen and oxygen radicals) [53], and mice with targeted lesions of IFN- $\gamma$ or its receptor are highly susceptible to intracellular infections including M. tuberculosis or Salmonella species $[54,55]$. Susceptibility to mycobacteria has also been observed in humans with inactivating mutations in the IFN- $\gamma$ gene. A major source of IFN- $\gamma$ in these infections is CD4 $\alpha \beta$ TCR Th1 cells, which are induced through antigen recognition on classi- cal MHC class II molecules, but early in the infection natural killer cells are also a source of this cytokine. The result of IFN- $y$ signalling is induction of nitrogen and oxygen free radicals as the key bacteriocidal mechanism [53]; tumour necrosis factor- $\alpha$ (TNF- $\alpha$ ) works in synergy with IFN- $\gamma$ in this regard [56], although TNF- $\alpha$ is secreted by macrophages as well as Th1 cells.

Th1-induced macrophage activation is presumably important for eliminating those commensal bacteria that succeed in penetrating the physical barriers of the intestine, although the evidence for this at present rests mainly on the translocation studies following $\mathrm{T}$ cell depletion in mice and the abundance of the Th1 subset present in the lamina propria. Natural killer cells are very rare in the intestine, but perhaps the high baseline activation of CD8 subsets within the mucosa (which is independent of luminal commensal bacteria [57]) renders the 'early response system' functionally unnecessary.

Animals with no $T$ cells may have increased penetration of commensal organisms into the body (and are fairly fragile even within a clean pathogen-free animal facility), but the phenotype is much less severe than the gp91phox ${ }^{-/} / \mathrm{NOS}^{-/}$double knockout, so the current lack of good functional assays for systemic bacterial penetration means that it is hard to know whether the induction of macrophage bactericidal activity depends on specific Th1 CD4 recognition (in which case, penetration would be considerably increased in animals with a highly restricted TCR repertoire, for example a TCR-transgenic strain crossed onto the $\mathrm{RAG}^{-/}$background). We would argue that this is likely given the significant induction of conventional CD4 T cells (signalling through the $\alpha \beta \mathrm{TCR}$ from peptides presented on class II MHC) following bacterial colonisation of a previously germ-free intestine, as discussed above.

What about non-classical antigen presentation mechanisms that signal to $\mathrm{T}$ cells through pathways other than the $\alpha \beta$ TCR? Here again, we can draw on some lessons from pathogens, but to extrapolate the exact mechanisms for commensals is harder. Human $\gamma \delta \mathrm{T}$ intraepithelial $\mathrm{T}$ cells clearly recognise the atypical HLA class I molecules MICA and MICB through the NKG2D receptor (originally defined as a natural killer cell receptor) and possibly also the $\gamma \delta$ TCR $[58,59]$. MIC molecules are expressed in response to cellular stress, for example adhesion of enteropathogenic Escherichia coli to intestinal epithelial Caco-2 cells in culture [60]. This effect is due to the interaction of bacterial AfaE-III adhesin with the CD55 receptor (decay-accelerating factor which inhibits C3 convertase). If the mechanism also works in vivo, $\gamma \delta$ $\mathrm{T}$ cells might eliminate those enterocytes that are signalling adherence of bacteria [61]. The extrapolation to commensals (if any) is fundamentally different from the discussion presented in the previous section in relation to macrophage phagocytosis; there we described how 
pathogens circumvent phagocytic mechanisms, here we are dealing with an essentially pathogenic adhesion mechanism which is absent in non-invasive strains. However, the possibility remains that (through undefined enterocyte signalling mechanisms) the occurrence of abnormal commensal bacerial biofilms on the enterocyte layer may cause disruptive innate immune interactions.

\section{Interactions between $B$ and $T$ lymphocytes in avoid- ing translocation of commensal intestinal bacteria}

The classical experiments of Gowans and Cebra and their coworkers showed that B cells are induced to switch to IgA expression in the Peyer's patches of the intestine, and subsequently migrate through the mesenteric lymphatics [62-65]. These cells later home to the intestinal lamina propria, and secrete IgA which becomes coupled to a specific protein carrier (polymeric immunoglobulin receptor, $\mathrm{pIgR}$ ) on the basolateral surface of epithelial cells $[66,67]$. The pIgR-IgA complex is endocytosed and the vesicles transit across the epithelial cells and release IgA on the luminal surface.

The number of intestinal lamina propria plasma cells and the amount of IgA that is secreted into the intestine are highly dependent on the presence of the commensal bacteria. This is shown by the sparse presence of intestinal IgA in germ-free animals. The sequence of changes following the introduction of commensal bacteria in the mucosal immune system has been studied by inoculation of wild-type $(\mathrm{C} 3 \mathrm{H})$ germ-free animals with a single gram-negative commensal organism (Morganella morgani) [68]. In these experiments, the previously germfree animals were kept throughout in an isolator, so that no other commensals or pathogens interfered with the results. At first, M. morgani was culturable from the mesenteric lymph nodes and the spleen, and prominent germinal centre reactions were visible in the Peyer's patches. Over approximately 3-4 weeks, the IgA content of the intestinal lamina propria increased, and the degree of penetration of M. morgani (measured by culturability) decreased, at first from the spleen and 2-3 weeks later from the mesenteric lymph nodes. Of course, whilst the induction of $\operatorname{IgA}$ follows about the same time-course as the abrogation of commensal bacterial translocation, as described in the previous section, IgA is not the only adaptive change as the intestine becomes colonised, so one cannot say how much it limits the penetration of commensals per se.

Experiments using cholera toxin to induce specific $\operatorname{IgA}$ in the intestine (and simultaneously in the serum) suggested that the process of IgA induction was dependent on interactions between B and T lymphocytes [69-75]. However, the presence of $\operatorname{IgA}$ in the serum and intestine in animals which lacked $\mathrm{T}$ cells because of genetically targeted ('knockout') lesions in the $\beta$ and $\delta$ TCR genes (TCR $\beta$ '$\delta^{--}$) indicated that IgA is also potentially induced through T cell-independent means [76].

Using strains of bacteria that express novel proteins when they colonise the mouse intestine, we found that T-independent IgA could be induced in response to changes in the antigen repertoire of the intestine [76]. T-independent $\operatorname{IgA}$ is derived from differentiation of a special class of $\mathrm{B}$ lymphocytes (B1). Unlike the conventional B2 lymphocytes which constitute most B cells in the secondary lymphoid organs (i.e. spleen, lymph nodes and Peyer's patches), B1 cells in adult rodents are derived from precursors in the pleuroperitoneal cavities rather than the bone marrow.

Normally, B cells need to express surface $\mu$ (the heavy chain of $\operatorname{IgM}$ ) in order to complete their differentiation pathway; they can then switch from expression of IgM to other isotypes (e.g. IgA, $\alpha$ heavy chain) by looping out the DNA segments between the $\mu$ and $\alpha$ genes during peripheral stimulation [77]. Peyer's patches have long been recognised as an important site of the $\mu \rightarrow \alpha$ switch [65], but recently, Fagarasan and coworkers [78] showed that this can also happen in the lamina propria outside organised lymphoid structures [78]. This is likely to be the site where T-independent IgA is induced, whereas the Peyer's patches are responsible for the T-dependent response.

There is still no direct evidence that secretory $\operatorname{IgA}$ protects the mucosa from the penetration or effects of commensal microorganisms or their products. Still less do we know the relative importance of T-dependent or T-independent $\operatorname{IgA}$ in these protective effects. There is, however, some indirect evidence for protection. First, mice which lack the pIgR, which transports IgA across epithelial cells into the lumen, have underlying mucosal inflammation which manifests as a protein-losing enteropathy [79]. Secondly, we can tell that mice with a targeted deletion of IgA expression $\left(\operatorname{IgA}^{--}\right)$have increased penetration of commensal bacteria, because whereas there is normally no systemic priming of serum IgG by commensal organisms when mice are kept in SPF conditions, this does occur in $\operatorname{IgA}^{-/}$ animals and in other strains (e.g aly/aly) with defective mucosal IgA production [76]. These indirect experiments illustrate our need for better readouts of the influence of IgA induced by the different pathways on bacterial densities adjacent to the epithelial cell layer and the propensity of commensals to penetrate into the mucosa.

\section{Interactions between T lymphocytes and intestinal epithelial cells}

The epithelial cell layer itself has very important immune functions that are relevant to protection from the penetration of commensal intestinal organisms apart from merely maintaining the intestinal lumen/mucosal barrier and 
transporting $\operatorname{IgA}$ into the lumen. Epithelial physiology is profoundly influenced by the presence of the commensal flora $[80,81]$. Enterocytes have the potential to produce reactive nitrogen radicals, to upregulate the inducible form of cyclooxygenase which results in the production of prostaglandins and in turn alters enterocyte secretory functions and to produce antimicrobial peptides (defensins/ cryptdins). They also directly modulate intestinal lymphocyte populations and functions $[82,83]$; such modulation may occur in the absence of the commensal microflora [40]. There is cell culture evidence that $\gamma \delta$ T cells can both enhance growth of epithelial cells through secretion of keratinocyte growth factors $[84,85]$ and target damaged enterocytes for destruction through MICA/B interactions with NKG2D as described above. However, the relevance of these effects in vivo with respect to containing nonpathogenic commensal bacteria remains unclear.

\section{What is a commensal organism?}

In this review, we have argued that although commensal bacteria penetrate in relatively small proportions, experimental evidence indicates that some do 'translocate' into the tissues of the body. Obviously, a small proportion of a prodigious bacterial load is still functionally significant. Many of the pattern-recognition receptors and immune mechanisms that deal with pathogens must be identical to those that are used for those commensal bacteria that penetrate immune defences; here, we have therefore looked at ways in which pathogens subvert immune mechanisms, on the assumption that these work perfectly well for a nonpathogen. Thus the essential difference between an organism that (in normal circumstances) is a commensal and those that are pathogens is that the commensals have not evolved to a niche that depends on overcoming mucosal and central immune defences that are internal (mucosal/serosal) to the epithelial cell layer. Presumably, the reason for this is that the main existence of the species is in the intestinal lumen, so its evolution has concentrated on adaptation to that luminal environment.

An interesting problem presents itself as to where the line should be drawn anatomically for what is accepted (tolerated or ignored) by the immune system in terms of commensals and their products. This review has concentrated on the interaction between $\mathrm{T}$ cells and commensal bacteria, although there are clearly abundant secreted innate factors that are bacteriostatic or bacteriocidal (e.g. cryptdins, defensins) that are $\mathrm{T}$ cell independent. There is evidence in culture systems that at low concentrations, such factors can be more effective in preventing biofilm layer formation than they are at inhibiting bacterial growth per se [86]. Ex vivo analysis of intestinal biofilms is in its infancy, but we suggest that these secreted factors (and IgA) limit biofilms that are adherent or very close to the epithelial cell layer. The plasticity of the IgA response presumably allows some adaptation, whether induced dependently or independently of $\mathrm{T}$ cells, to the current flora of the intestine. Whether biofilms residing close to epithelial cells in the mucus layer can trigger innate responses from T cells to disrupt 'distressed' epithelial cells (as happens for adherent pathogens) remains to be seen. The line of respond/ignore used by the mucosal immune system is therefore blurred by the diversity of possible innate and adaptive responses; we still need to obtain much better direct data on the mechanisms that each of these immune arms uses to contain the commensals largely within the intestinal lumen.

1 Bjarnason I., Macpherson A. J. and Hollander D. (1995) Intestinal permeability: an overview. Gastroenterology 108: 1566- 1581 .

2 Benveniste J., Lespinats G. and Salomon J. (1971) Serum and secretory IgA in axenic and holoxenic mice. J. Immunol. 107: 1656-1662

3 Benveniste J., Lespinats G., Adam C. and Salomon J. C. (1971) Immunoglobulins in intact, immunized, and contaminated axenic mice: study of serum IgA. J. Immunol. 107:1647-1655

4 Haury M., Sundblad A., Grandien A., Barreau C., Coutinho A. and Nobrega A. (1997) The repertoire of IgM in normal mice is largely independent of external antigenic contact. Eur. J. Immunol. 27: 1557-1563

5 Hooijkaas H., Benner R., Pleasants J. R. and Wostmann B. S. (1984) Isotypes and specificities of immunoglobulins produced by germ-free mice fed chemically defined ultrafiltered ,antigen-free" diet. Eur. J. Immunol. 14: 1127-1130

6 Cascalho M., Wong J. and Wabl M. (1997) VH gene replacement in hyperselected B cells of the quasimonoclonal mouse. J. Immunol. 159: 5795-5801

7 Cascalho M., Ma A., Lee S., Masat L. and Wabl M. (1996) A quasi-monoclonal mouse. Science 272: 1649-1652

8 Benedict C. L. and Kearney J. F. (1999) Increased junctional diversity in fetal B cells results in a loss of protective anti-phosphorylcholine antibodies in adult mice. Immunity 10: 607-617

9 Benoist C. and Mathis D. (2001) Autoimmunity provoked by infection: how good is the case for T cell epitope mimicry? Nat. Immunol. 2: 797-801

10 Moreau M. C., Ducluzeau R., Guy-Grand D. and Muller M. C. (1978) Increase in the population of duodenal immunoglobulin A plasmocytes in axenic mice associated with different living or dead bacterial strains of intestinal origin. Infect. Immun. 21: $532-539$

11 Macpherson A. J., Hunziker L., McCoy K. and Lamarre A. (2001) IgA responses in the intestinal mucosa against pathogenic and non-pathogenic microorganisms. Microbes Infec.t 3: $1021-1035$

12 Guy-Grand D., Cerf-Bensussan N., Malissen B., Malassis-Seris M., Briottet C. and Vassalli P. (1991) Two gut intraepithelial CD8+ lymphocyte populations with different $\mathrm{T}$ cell receptors: a role for the gut epithelium in T cell differentiation. J. Exp. Med. 173: 471-481

13 Poussier P. and Julius M. (1994) Intestinal intraepithelial lymphocytes: the plot thickens. J. Exp. Med. 180: 1185-1189

14 Poussier P., Edouard P., Lee C., Binnie M. and Julius M. (1992) Thymus-independent development and negative selection of T cells expressing $\mathrm{T}$ cell receptor alpha/beta in the intestinal epithelium: evidence for distinct circulation patterns of gut-and thymus-derived T lymphocytes. J. Exp. Med. 176: 187-199

15 Umesaki Y., Setoyama H., Matsumoto S. and Okada Y. (1993) Expansion of alpha beta T-cell receptor-bearing intestinal in- 
traepithelial lymphocytes after microbial colonization in germfree mice and its independence from thymus. Immunology 79: $32-37$

16 Helgeland L., Vaage J. T., Rolstad B., Midtvedt T. and Brandtzaeg P. (1996) Microbial colonization influences composition and T-cell receptor $\mathrm{V}$ beta repertoire of intraepithelial lymphocytes in rat intestine. Immunology 89: 494-501

17 Helgeland L., Vaage J. T., Rolstad B., Halstensen T. S., Midtvedt T. and Brandtzaeg P. (1997) Regional phenotypic specialization of intraepithelial lymphocytes in the rat intestine does not depend on microbial colonization. Scand. J. Immunol. 46: $349-357$

18 Takimoto H., Nakamura T., Takeuchi M., Sumi Y., Tanaka T., Nomoto K. et al. (1992) Age-associated increase in number of $\mathrm{CD} 4+\mathrm{CD} 8+$ intestinal intraepithelial lymphocytes in rats. Eur. J. Immunol. 22: 159-164

19 Leishman A. J., Naidenko O. V., Attinger A., Koning F., Lena C. J., Xiong Y. et al. (2001) T cell responses modulated through interaction between CD8alphaalpha and the nonclassical MHC class I molecule, TL. Science 294: 1936-1939

20 Takeuchi M., Miyazaki H., Mirokawa K., Yokokura T. and Yoshikai Y. (1993) Age-related changes of T cell subsets in intestinal intraepithelial lymphocytes of mice. Eur. J. Immunol. 23: $1409-1411$

21 Zinkernagel R. M., Callahan G. N., Klein J. and Dennert G. (1978) Cytotoxic T cells learn specificity for self $\mathrm{H}-2$ during differentiation in the thymus. Nature 271: 251-253

22 Fink P. J. and Bevan M. J. (1978) H-2 antigens of the thymus determine lymphocyte specificity. J. Exp. Med. 148: 766-775

23 Zinkernagel R. M., Althage A. and Callahan G. (1979) Thymic reconstitution of nude F1 mice with one or both parental thymus grafts. J. Exp. Med. 150: 693-697

24 Teh H. S., Kisielow P., Scott B., Kishi H., Uematsu Y., Bluthmann H. et al. (1988) Thymic major histocompatibility complex antigens and the alpha beta T-cell receptor determine the CD4/CD8 phenotype of T cells. Nature 335: 229-233

25 Kisielow P., Teh H. S., Bluthmann H. and Boehmer H. von (1988) Positive selection of antigen-specific T cells in thymus by restricting MHC molecules. Nature 335: 730-733

26 Sha W. C., Nelson C. A., Newberry R. D., Kranz D. M., Russell J. H. and Loh D. Y. (1988) Positive and negative selection of an antigen receptor on $T$ cells in transgenic mice. Nature 336: $73-76$

27 Berg L. J., Pullen A. M., Fazekas de St Groth B., Mathis D., Benoist C. and Davis M. M. (1989) Antigen/MHC-specific T cells are preferentially exported from the thymus in the presence of their MHC ligand. Cell 58: 1035-1046

28 Das G. and Janeway C. A. Jr (1999) Development of CD8alpha/alpha and CD8alpha/beta T cells in major histocompatibility complex class I-deficient mice. J. Exp. Med. 190: 881-884

29 Rocha B., Boehmer H. von and Guy-Grand D. (1992) Selection of intraepithelial lymphocytes with CD8 alpha/alpha co-receptors by self-antigen in the murine gut. Proc. Natl. Acad. Sci. USA 89: 5336-5340

30 Cruz D., Sydora B. C., Hetzel K., Yakoub G., Kronenberg M. and Cheroutre H. (1998) An opposite pattern of selection of a single $\mathrm{T}$ cell antigen receptor in the thymus and among intraepithelial lymphocytes. J. Exp. Med. 188: 255-265

31 Miyawaki S., Nakamura Y., Suzuka H., Koba M., Yasumizu R., Ikehara S. et al. (1994) A new mutation, aly, that induces a generalized lack of lymph nodes accompanied by immunodeficiency in mice. Eur. J. Immunol. 24: 429-434

32 Matsumoto M., Iwamasa K., Rennert P. D., Yamada T., Suzuki R., Matsushima A. et al. (1999) Involvement of distinct cellular compartments in the abnormal lymphoid organogenesis in lymphotoxin-alpha-deficient mice and alymphoplasia (aly) mice defined by the chimeric analysis. J. Immunol. 163: 1584- 1591

33 Macpherson A. J., Lamarre A., McCoy K., Dougan G., Harriman G., Hengartner H. et al. (2001) IgA B cell and IgA anti- body production in the absence of mu and delta heavy chain expression early in B cell ontongeny. Nat. Immunol. 2: 625-631

34 Kanamori Y., Ishimaru K., Nanno M., Maki K., Ikuta K., Nariuchi H. et al. (1996) Identification of novel lymphoid tissues in murine intestinal mucosa where clusters of c-kit+ IL-7R+ Thy $1+$ lympho-hemopoietic progenitors develop. J. Exp. Med. 184:1449-1459

35 Guy-Grand D. and Vassalli P. (2002) Gut intraepithelial lymphocyte development. Curr. Opin. Immunol. 14: 255-259

36 Arstila T., Arstila T. P., Calbo S., Selz F., Malassis-Seris M., Vassalli P. et al. (2000) Identical T cell clones are located within the mouse gut epithelium and lamina propia and circulate in the thoracic duct lymph. J. Exp. Med. 191: 823-834

37 Saito H., Kanamori Y., Takemori T., Nariuchi H., Kubota E. Takahashi-Iwanaga H. et al. (1998) Generation of intestinal T cells from progenitors residing in gut cryptopatches. Science 280: $275-278$

38 Das G., Gould D. S., Augustine M. M., Fragoso G., Sciutto E., Stroynowski I. et al. (2000) Qa-2-dependent selection of CD8alpha/alpha $\mathrm{T}$ cell receptor alpha/beta $(+)$ cells in murine intestinal intraepithelial lymphocytes. J. Exp. Med. 192: 1521 1528.

39 Fujiura Y., Kawaguchi M., Kondo Y., Obana S., Yamamoto H., Nanno M. et al. (1996) Development of CD8 alpha alpha+ intestinal intraepithelial $\mathrm{T}$ cells in beta 2-microglobulin- and/or TAP1-deficient mice. J. Immunol. 156: 2710-2715

40 Mysorekar I. U., Lorenz R. G. and Gordon J. I. (2002) A gnotobiotic transgenic mouse model for studying interactions between small intestinal enterocytes and intraepithelial lymphocytes. J. Biol. Chem. 22: 22

41 O'Boyle C. J., MacFie J., Mitchell C. J., Johnstone D., Sagar P. M. and Sedman P. C. (1998) Microbiology of bacterial translocation in humans. Gut 42: 29-35

42 Tancrede C. H. and Andremont A. O. (1985) Bacterial translocation and gram-negative bacteremia in patients with hematological malignancies. J. Infect. Dis. 152: 99-103

43 Witt D. J., Craven D. E. and McCabe W. R. (1987) Bacterial infections in adult patients with the acquired immune deficiency syndrome (AIDS) and AIDS-related complex. Am. J. Med. 82: 900-906

44 Owens W. E. and Berg R. D. (1980) Bacterial translocation from the gastrointestinal tract of athymic $(\mathrm{nu} / \mathrm{nu})$ mice. Infect. Immun. 27: 461-467

45 Berg R. D. (1996) The indigenous gastrointestinal microflora. Trends Microbiol. 4: 430-435

46 Gautreaux M. D., Gelder F. B., Deitch E. A. and Berg R. D. (1995) Adoptive transfer of T lymphocytes to T-cell-depleted mice inhibits Escherichia coli translocation from the gastrointestinal tract. Infect. Immun. 63: 3827-3834

47 Shiloh M. U., MacMicking J. D., Nicholson S., Brause J. E., Potter S., Marino M. et al. (1999) Phenotype of mice and macrophages deficient in both phagocyte oxidase and inducible nitric oxide synthase. Immunity 10: 29-38

48 Blocker A., Gounon P., Larquet E., Niebuhr K., Cabiaux V., Parsot C. et al. (1999) The tripartite type III secreton of Shigella flexneri inserts IpaB and IpaC into host membranes. J. Cell. Biol. 147: 683-693

49 Sansonetti P. (2001) Phagocytosis of bacterial pathogens: implications in the host response. Semin. Immunol. 13: 381-390

50 Persson C., Carballeira N., Wolf-Watz H. and Fallman M. (1997) The PTPase YopH inhibits uptake of Yersinia, tyrosine phosphorylation of p130Cas and FAK, and the associated accumulation of these proteins in peripheral focal adhesions. EMBO J. 16: 2307-2318

51 Zumbihl R., Aepfelbacher M., Andor A., Jacobi C. A., Ruckdeschel K., Rouot B. et al. (1999) The cytotoxin YopT of Yersinia enterocolitica induces modification and cellular redistribution of the small GTP-binding protein RhoA. J. Biol. Chem. 274: 29289-2993 
52 Black D. S. and Bliska J. B. (2000) The RhoGAP activity of the Yersinia pseudotuberculosis cytotoxin YopE is required for antiphagocytic function and virulence. Mol. Microbiol. 37: $515-527$

53 Boehm U., Klamp T., Groot M. and Howard J. C. (1997) Cellular responses to interferon-gamma. Annu. Rev. Immunol. 15: $749-795$

54 Flynn J. L., Chan J., Triebold K. J., Dalton D. K., Stewart T. A. and Bloom B. R. (1993) An essential role for interferon gamma in resistance to Mycobacterium tuberculosis infection. J. Exp. Med. 178: 2249-2254

55 Cooper A. M., Dalton D. K., Stewart T. A., Griffin J. P., Russell D. G. and Orme I. M. (1993) Disseminated tuberculosis in interferon gamma gene-disrupted mice. J. Exp. Med. 178: 2243-2247

56 Flynn J. L., Goldstein M. M., Chan J., Triebold K. J., Pfeffer K., Lowenstein C. J. et al. (1995) Tumor necrosis factor-alpha is required in the protective immune response against Mycobacterium tuberculosis in mice. Immunity 2: $561-572$

57 Sydora B. C., Mixter P. F., Holcombe H. R., Eghtesady P., Williams K., Amaral M. C. et al. (1993) Intestinal intraepithelial lymphocytes are activated and cytolytic but do not proliferate as well as other T cells in response to mitogenic signals. J. Immunol. 150: 2179-2191

58 Bauer S., Groh V., Wu J., Steinle A., Phillips J. H., Lanier L. L. et al. (1999) Activation of NK cells and T cells by NKG2D, a receptor for stress-inducible MICA. Science 285: 727-729

59 Groh V., Steinle A., Bauer S. and Spies T. (1998) Recognition of stress-induced MHC molecules by intestinal epithelial gammadelta T cells. Science 279: $1737-1740$

60 Suemizu H., Radosavljevic M., Kimura M., Sadahiro S., Yoshimura S., Bahram S. et al. (2002) A basolateral sorting motif in the MICA cytoplasmic tail. Proc. Natl. Acad. Sci. USA 99: $2971-2976$

61 Spies T. (2002) Induction of T cell alertness by bacterial colonization of intestinal epithelium. Proc. Natl. Acad. Sci. USA 99: $2584-2586$

62 Pierce N. F. and Gowans J. L. (1975) Cellular kinetics of the intestinal immune response to cholera toxoid in rats. J. Exp. Med. 142: $1550-1563$

63 Gowans J. L. and Knight E. J. (1964) The route of recirculation of lymphocytes in the rat. Proc. R. Soc. B 159: 257-282

64 Husband A. J. and Gowans J. L. (1978) The origin and antigendependent distribution of IgA-containing cells in the intestine. J. Exp. Med. 148: 1146-1160

65 Craig S. W. and Cebra J. J. (1971) Peyer's patches: an enriched source of precursors for IgA-producing immunocytes in the rabbit. J. Exp. Med. 134:188-200

66 Brandtzaeg P. and Prydz H. (1984) Direct evidence for an integrated function of $\mathrm{J}$ chain and secretory component in epithelial transport of immunoglobulins. Nature 311: 71-73

67 Brandtzaeg P., Krajci P., Lamm M.E. and Kaetzel C. S. (1994) Epithelial and hepatobiliary transport of polymeric immunoglobulins. In: Handbook of Mucosal Immunology, pp. 113-126, Ogra P. L. (ed.), Academic Press, San Diego

68 Shroff K. E., Meslin K. and Cebra J. J. (1995) Commensal enteric bacteria engender a self-limiting humoral mucosal immune response while permanently colonizing the gut. Infect. Immun. 63: 3904-3913

69 Vajdy M., Kosco-Vilbois M. H., Kopf M., Kohler G. and Lycke N. (1995) Impaired mucosal immune responses in interleukin 4-targeted mice. J. Exp. Med. 181: 41-53
70 Bromander A. K., Ekman L., Kopf M., Nedrud J. G. and Lycke N. Y. (1996) IL-6-deficient mice exhibit normal mucosal IgA responses to local immunizations and Helicobacter felis infection. J. Immunol. 156: 4290-4297

71 Gardby E., Lane P. and Lycke N. Y. (1998) Requirements for B7-CD28 costimulation in mucosal IgA responses: paradoxes observed in CTLA4-H gamma 1 transgenic mice. J. Immunol. 161: $49-59$

72 Hörnquist C. E., Ekman L., Grdic K. D., Schön K. and Lycke N. Y. (1995) Paradoxical IgA immunity in CD4-deficient mice. J. Immunol. 155: 2877-2887

73 Lycke N. and Holmgren J. (1986) Intestinal mucosal memory and presence of memory cells in lamina propria and Peyer's patches in mice 2 years after oral immunization with cholera toxin. Scand. J. Immunol. 23: 611-616

74 Lycke N., Eriksen L. and Holmgren J. (1987) Protection against cholera toxin after oral immunisation is thymus dependent and associated with intestinal production of neutralising IgA antitoxin. Scand. J. Immunol. 25: 413-419

75 Lycke N., Erlandsson L., Ekman L., Schon K. and Leanderson T. (1999) Lack of J chain inhibits the transport of gut IgA and abrogates the development of intestinal antitoxic protection. J. Immunol. 163: 913-919

76 Macpherson A. J., Gatto D., Sainsbury E., Harriman G. R., Hengartner H. and Zinkernagel R. M. (2000) A primitive T cellindependent mechanism of intestinal mucosal IgA responses to commensal bacteria. Science 288: 2222-2226

77 Snapper C. M. and Finkelman F. D. (1999) Immunoglobulin class switching. In: Fundamental Immunology, 4th edn. pp. 831-861, Paul W. E. (ed.), Lippincott-Raven, Philadelphia

78 Fagarasan S., Kinoshita K., Muramatsu M., Ikuta K. and Honjo T. (2001) In situ class switching and differentiation to IgA-producing cells in the gut lamina propria. Nature 413: 639-643

79 Johansen F. E., Pekna M., Norderhaug I. N., Haneberg B., Hietala M. A., Krajci P. et al. (1999) Absence of epithelial immunoglobulin A transport, with increased mucosal leakiness, in polymeric immunoglobulin receptor/secretory component-deficient mice. J. Exp. Med. 190: 915-922

80 Hooper L. V., Wong M. H., Thelin A., Hansson L., Falk P. G. and Gordon J. I. (2001) Molecular analysis of commensal hostmicrobial relationships in the intestine. Science 291: $881-$ 884

81 Hooper L. V. and Gordon J. I. (2001) Commensal host-bacterial relationships in the gut. Science 292: 1115-1118

82 Yamamoto M., Fujihashi K., Kawabata K., McGhee J. R. and Kiyono H. (1998) A mucosal intranet: intestinal epithelial cells down-regulate intraepithelial, but not peripheral, T lymphocytes. J. Immunol. 160: 2188-2196

83 Kagnoff M. F. and Eckmann L. (1997) Epithelial cells as sensors for microbial infection. J. Clin. Invest. 100: 6-10

84 Boismenu R. and Havran W. L. (1994) Modulation of epithelial cell growth by intraepithelial gamma delta T cells. Science 266: $1253-1255$

85 Jameson J., Ugarte K., Chen N., Yachi P., Fuchs E., Boismenu R. et al. (2002) A role for skin gammadelta T cells in wound repair. Science 296: 747-749

87 Singh P. K., Parsek M.R., Greenberg E. P. and Welsh M. J. (2002) A component of innate immunity prevents bacterial biofilm development. Nature 417: 552-555 